\title{
Analysis of the Conditions of Luzhou-Flavor Liquor Based on Information Fusion
}

\author{
Haijiao Luo, Ge Li, Yi Yao* \\ School of Automation and Information Engineering of Sichuan University of Science \& Engineering, Yibin, China \\ Email: ^1256742196@qq.com
}

How to cite this paper: Luo, H.J., Li, G. and Yao, Y. (2019) Analysis of the Conditions of Luzhou-Flavor Liquor Based on Information Fusion. Open Access Library Journal, 6: e5754.

https://doi.org/10.4236/oalib.1105754

Received: September 2, 2019

Accepted: September 17, 2019

Published: September 20, 2019

Copyright $\odot 2019$ by author(s) and Open Access Library Inc.

This work is licensed under the Creative Commons Attribution International License (CC BY 4.0).

http://creativecommons.org/licenses/by/4.0/

\begin{abstract}
The fermentation process of Luzhou-flavor liquor is almost uncontrollable, and at the same time, in his production process, the fermentation method is utilized. Therefore, eel conditions are an important reference indicator for liquor fermentation. In the study of the conditions for the emergence of Luzhou-flavor liquor, the quantitative evaluation of the conditions of liquor discharge was achieved by the cloud model and the improved D-S (Dempater-Shafer) evidence theory. There are five main factors that have a profound influence on the sputum conditions, namely temperature, moisture, acidity, starch content and reducing sugar. The membership degree cloud model is established by Matlab simulation for the out-of-the-box condition, so that each parameter has its corresponding membership function. The collected sample parameters are used to realize the membership degree of each evaluation standard through the cloud model, and the sample data are analyzed by using the improved D-S evidence theory. Through experimental analysis, the outburst condition of liquor can reach a more accurate quantitative analysis, so as to guide the fermentation process of Luzhou-flavor liquor, and then improve its yield and quality.
\end{abstract}

\section{Subject Areas \\ Multimedia/Signal Processing}

\section{Keywords}

Liquor Fermentation, Retrograde Fermentation, Exit Conditions, Cloud Model D-S Evidence Theory, Information Fusion

\section{Introduction}

During production of Luzhou-flavor liquor, the fermentation of Luzhou-flavor liquor is an anaerobic, solid, and closed process. Solid fermentation is used 
throughout the fermentation, and it is not easy to check the parameters in the middle of the fermentation [1]. At the same time, a new wine cellar is in addition to the wine cellar that has been repeatedly fermented for a long time, and a new wine cellar is brought to the old wine cellar. Most domestic Luzhou-flavored wineries do not strictly control the proportion of temperature, moisture, acidity, starch content and reducing sugar in the wine cellar, mainly depending on artificial experience. Therefore, the content of each component of the wine cellar will directly affect the fermentation quality of the next cellar. Therefore, analysis of the plutonium condition has an important guiding effect on the production process of the late liquor, and can determine the yield and quality of the final liquor.

The main parameters of Luzhou-flavor liquor were analyzed by Matlab to establish the membership degree cloud model of each outflow condition, and the cloud model membership degree of sample parameters was obtained, and the improved D-S evidence theory was used for information fusion. Finally, the conditions for the liquor production were evaluated.

\section{Analysis of the Conditions for the Emergence of Luzhou-Flavor Liquor}

\subsection{Temperature}

Each bacterium and microorganism have its optimum temperature for growth and reproduction. Luzhou-flavored kanji is slowly fermented by solid low temperature. The temperature of the exit will influence the quality of the fermentation. The most suitable exit temperature is between $24^{\circ} \mathrm{C}$ and $28^{\circ} \mathrm{C}$. Excessive temperature in the early stage is too high, resulting in faster acid production, resulting in higher acidity of the sputum; too low fermentation process is not ideal, which has a greater impact on the production and quality of white wine.

\subsection{Moisture}

Water is not only the basic condition for microbial survival and metabolism. But also an important carrier for mass transfer and heat transfer during fermentation. The most suitable moisture for the cockroach is $60 \%-62 \%$. The specific heat and specific gravity of water, combined with its unique permeability, fluidity and solubility, therefore, the level of moisture has a greater impact on the sputum. If the moisture is too high, it will cause excessive gelatinization, which will lead to undue heat temperature. If the water is too small, it will cause the aerobic bacteria to multiply and affect the flavor of the wine.

\subsection{Acidity}

Suitable acid in the fermentation process can hydrolyze starch, fiber and the like into sugar (glucose), which is beneficial to gelatinization, saccharification and fermentation, and the yield and quality of the wine are improved. Acid is not just a precursor of ester, but because yeast has certain acid resistance, suitable acid can inhibit the growth and reproduction of some harmful bacteria without 
affecting the fermentation ability of yeast. The suitable acidity of the sputum is $4.0-4.8 \mathrm{~mol} / \mathrm{L}$. Too low acidity will lead to the proliferation of miscellaneous bacteria, wasting sugar and starch; too high will inhibit the activity of yeast and affect the yield of wine.

\subsection{Starch}

In the fermentation, the starch decomposes into fermentable sugar, and the yeast uses these sugars to ferment to produce alcohol. The suitable concentration of the starch is $11 \%$ - $13 \%$. Too high will lead to insufficient fermentation, too much residue, not only waste, but also cause harmful acid bacteria to multiply and cause rancidity; when too low, the starch content cannot meet The need for microorganisms during a single fermentation process results in reduced production efficiency and affects the quality of the wine [1].

\subsection{Reducing Sugar}

During the fermentation process, the starch will be decomposed into reduction, and the sugar yeast will use these sugars to ferment to produce alcohol. The reducing sugar content is $0.5 \%-1 \%$, and the reducing sugar content is too high, indicating that the saccharification enzyme saccharification is better, but the yeast is The fermentation process is relatively poor, and the fermentation in the pond is not sufficient; the low content will affect the low alcohol content in the next fermentation process.

\section{Construction of Basic Probability Assignment (BPA)}

Uncertainty is the concept of relative precision, including ambiguity and randomness. Fuzziness mainly refers to the uncertainty of subjective understanding, while randomness reflects the uncertainty of natural law [2]. The cloud model is a transformation model that expresses the uncertainty between the qualitative concept and its quantification [3]. Digital features are represented by three values: $E x, E n$ and $H e$. It combines ambiguity and randomness to form qualitative and quantitative. The mapping between the two serves as the basis for knowledge representation [4]. Ex is the distribution expectation of cloud droplets, and is the most typical quantitative sample of this concept; entropy En is a measure of qualitative concept uncertainty, including randomness and ambiguity, and randomness refers to the discreteness of cloud droplets that can reflect this concept. Fuzziness refers to the range of cloud drip values that can reflect the concept of the universe; super-entropy $H e$ is a measure of the uncertainty of $E n$, which is the entropy of entropy [5]. According to the actual production experience and research, the suitability of the exit conditions is judged, as showed in Table 1.

According to data of the outbound conditions, the exact value of the membership degree of different grades can be obtained. The sum of the membership degrees corresponding to the constant monitoring quantity is 1 . When the sum of the exact values is lower than 1 , the difference is attributed to the uncertainty 
item. The normalization condition that satisfies the basic probability distribution of DS evidence [6]. The distribution curve of the membership degree of the five major factors (temperature, moisture, acidity, starch, and reducing sugar) of liquor fermentation by Matlab simulation is shown in Figure 1.
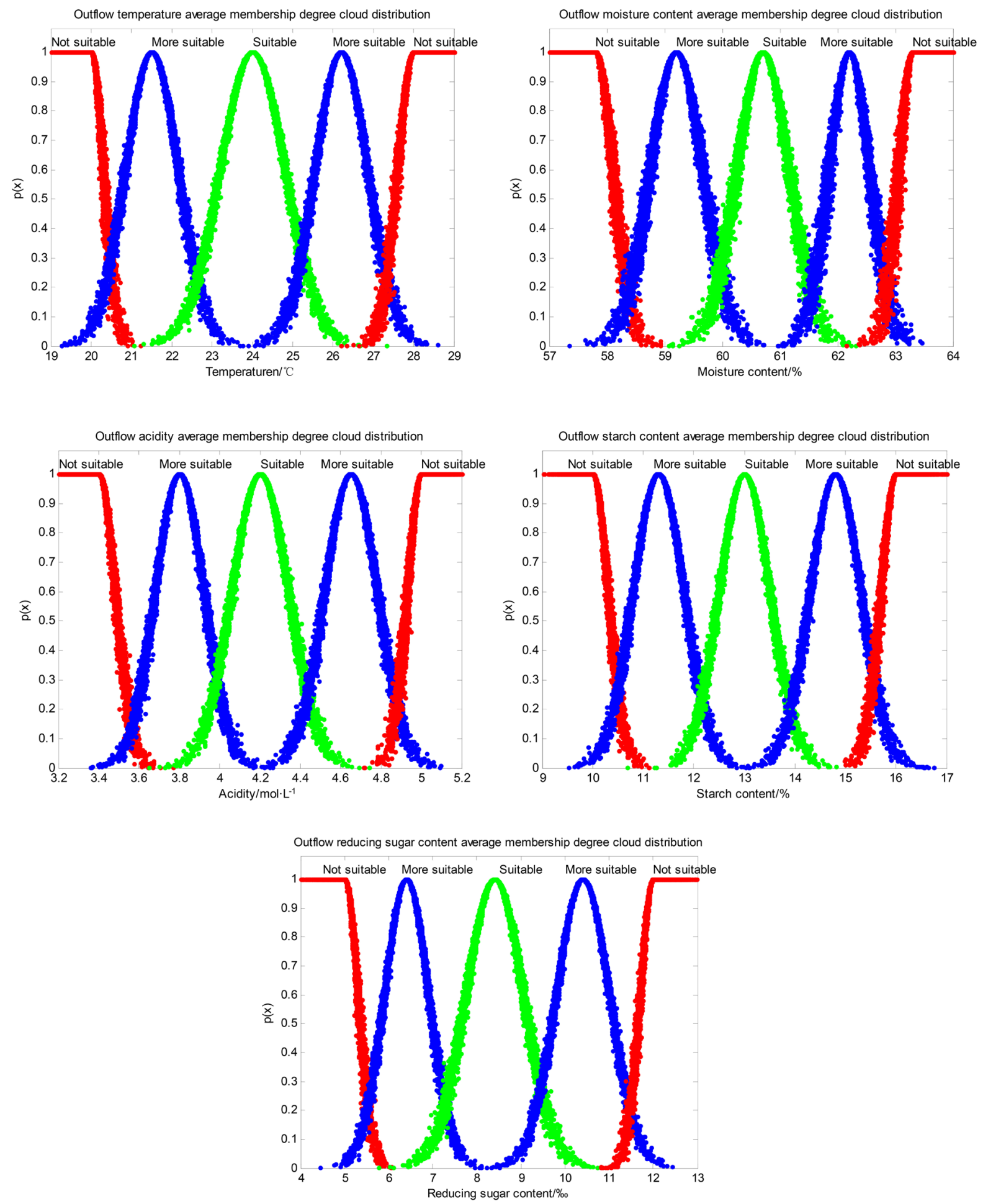

Figure 1. Distribution curve of the membership degree of the five major factors. 
Table 1. Exit condition level distribution.

\begin{tabular}{cccccc}
\hline & Temperature $/{ }^{\circ} \mathrm{C}$ & $\begin{array}{c}\text { Moisture } \\
/ \%\end{array}$ & $\begin{array}{c}\text { Acidity/ } \\
\mathrm{mol} \cdot \mathrm{L}^{-1}\end{array}$ & Starch/\% & $\begin{array}{c}\text { Reducing } \\
\text { sugar/\% }\end{array}$ \\
\hline Too low (not suitable) & $<20$ & $<58$ & $<3.4$ & $<11$ & $<0.5$ \\
Lower (better) & $20-22$ & $58-60$ & $3.4-4.0$ & $10-12$ & $0.5-0.7$ \\
suitable & $22-25$ & $60-62$ & $4.0-4.5$ & $12-14$ & $0.7-0.9$ \\
Higher (better) & $25-28$ & $62-63$ & $4.5-5.0$ & $14-16$ & $0.9-1.2$ \\
Too high (not suitable) & $>28$ & $>63$ & $>5.0$ & $>16$ & $>1.2$ \\
\hline
\end{tabular}

Data collected from a Luzhou-flavored winery are shown in Table 2. It is known from the basic probability distribution function (BPA) of the existing condition that the parameters of the sample 0 are basically within a suitable range. Sample 1 is under a slightly higher moisture content. Sample 2 is under a slightly lower acidity content. The starch content of sample 3 was slightly higher, respectively. The content of reducing sugar in sample 4 was slightly higher, respectively.

The sample data satisfying the normalization condition of the D-S evidence theory in Table 3 can be obtained from the basic probability distribution function (BPA) of the exit condition.

\section{Evidence Theory}

\subsection{Basic Content of Evidence Theory}

D-S evidence theory is the most commonly used fusion technique and was proposed by Dempater and Shafer in the 1960s. The evidence theory first defines $U$ as the recognition framework, $m$ is the basic credibility assignment on $U$, and $m$ satisfies:

$$
\left\{\begin{array}{l}
m(\varnothing)=0 \\
\sum_{(A \subseteq \Theta)} m(A)=1
\end{array}\right.
$$

In the formula (1), $A$ is a subset of $U$, and $\varnothing$ is an empty set. $m(A)$ is BPA (basic probability distribution function) indicating the degree of accurate trust of evidence against $A$ [7].

\subsection{Multiple Evidence for Synthesis}

$m_{1}, m_{2}$ are two BPAs on the $U$ (basic probability distribution function), and $A_{1}, A_{2}, \cdots, A_{k}, B_{1}, B_{2}, \cdots, B_{r}$ the focal points to be identified, then:

$$
m(A)= \begin{cases}\frac{Q}{1-K} & A \neq \varnothing \\ 0 & A=\varnothing\end{cases}
$$

In formula (2)

$$
Q=\sum_{A_{i} \cap B_{j}=A} m_{1}\left(A_{i}\right) m_{2}\left(B_{j}\right)
$$




$$
K=\sum_{A_{i} \cap B_{j}=\varnothing} m_{1}\left(A_{i}\right) m_{2}\left(B_{j}\right)
$$

$K$ is the coefficient of conflict, and the larger $K$, the greater the conflict. A value of 1 indicates a complete conflict, indicating that the rule is not available [8] [9].

Table 2. Data sample.

\begin{tabular}{cccccc}
\hline & Temperature $/{ }^{\circ} \mathrm{C}$ & Moisture/\% & Acidity/mol. $^{-1}$ & Starch/\% & $\begin{array}{c}\text { Reducing } \\
\text { sugar } \%\end{array}$ \\
\hline Sample 0 & 24.8 & 61.5 & 4.2 & 13.5 & 0.72 \\
Sample 1 & 25.6 & 63.32 & 3.82 & 12.26 & 0.64 \\
Sample 2 & 27.5 & 62.23 & 3.43 & 11.67 & 0.74 \\
Sample 3 & 23.6 & 58 & 4.58 & 16.39 & 1.7 \\
Sample 4 & 23.1 & 59.92 & 3.74 & 15.11 & 1.83 \\
\hline
\end{tabular}

Table 3. Basic probability distribution of detection parameters.

\begin{tabular}{|c|c|c|c|c|c|}
\hline \multicolumn{2}{|c|}{ Detection volume } & \multirow{2}{*}{$\begin{array}{c}\text { suitable } \\
\mathrm{m}(\mathrm{A} 1) \%\end{array}$} & \multirow{2}{*}{$\begin{array}{c}\text { More suitable } \\
\text { m(A2)\% }\end{array}$} & \multirow{2}{*}{$\begin{array}{l}\text { Not suitable } \\
\text { m(A3)\% } \\
0\end{array}$} & \multirow{2}{*}{$\begin{array}{c}\text { uncertain } \\
\mathrm{m}(\mathrm{X}) \%\end{array}$} \\
\hline & Temperature $/{ }^{\circ} \mathrm{C}$ & & & & \\
\hline & Moisture/\% & 29.92 & 24.51 & 0 & 45.57 \\
\hline \multirow[t]{5}{*}{ Sample 0} & Acidity $/ \mathrm{mol} \cdot \mathrm{L}^{-1}$ & 99.99 & 0.01 & 0 & 0 \\
\hline & starch/\% & 56.45 & 6.4 & 0 & 37.15 \\
\hline & Reducing sugar\% & 23.08 & 35.14 & 0 & 41.78 \\
\hline & Temperature $/{ }^{\circ} \mathrm{C}$ & 17.02 & 58.02 & 0 & 24.96 \\
\hline & Moisture /\% & 0 & 0 & 99.99 & 0.01 \\
\hline \multirow[t]{5}{*}{ Sample 1} & Acidity $/ \mathrm{mol} \cdot \mathrm{L}^{-1}$ & 1.42 & 98.4 & 0 & 0.18 \\
\hline & starch/\% & 35.43 & 22.25 & 0 & 42.32 \\
\hline & Reducing sugar\% & 0.12 & 99.88 & 0 & 0 \\
\hline & Temperature $/{ }^{\circ} \mathrm{C}$ & 0 & 19.42 & 33.8 & 46.78 \\
\hline & Moisture /\% & 0.24 & 99.76 & 0 & 0 \\
\hline \multirow[t]{5}{*}{ Sample 2} & Acidity $/ \mathrm{mol} \cdot \mathrm{L}^{-1}$ & 0 & 10.08 & 89.92 & 0 \\
\hline & $\operatorname{starch} / \%$ & 4.96 & 78.93 & 0 & 16.11 \\
\hline & Reducing sugar\% & 35.56 & 20.73 & 0 & 43.71 \\
\hline & Temperature $/{ }^{\circ} \mathrm{C}$ & 85.99 & 0.54 & 0 & 13.47 \\
\hline & Moisture /\% & 0 & 3.16 & 78.08 & 18.76 \\
\hline \multirow[t]{5}{*}{ Sample 3} & Acidity $/ \mathrm{mol} \cdot \mathrm{L}^{-1}$ & 3.32 & 84.12 & 0 & 12.56 \\
\hline & starch/\% & 0 & 0.01 & 99.99 & 0 \\
\hline & Reducing sugar\% & 0 & 0.01 & 99.99 & 0 \\
\hline & Temperature $/{ }^{\circ} \mathrm{C}$ & 46.46 & 5.8 & 0 & 47.74 \\
\hline & Moisture /\% & 32.92 & 36.02 & 0 & 31.06 \\
\hline \multirow[t]{3}{*}{ Sample 4} & Acidity $/ \mathrm{mol} \cdot \mathrm{L}^{-1}$ & 0 & 87.15 & 0.18 & 12.67 \\
\hline & starch/\% & 0 & 85.72 & 2.48 & 11.8 \\
\hline & Reducing sugar\% & 0 & 0.01 & 99.99 & 0 \\
\hline
\end{tabular}




\section{Improvement of Evidence Theory}

\subsection{Calculate the Average Mass Function of Each Evidence}

$$
\bar{m}\left(A_{k}\right)=\frac{1}{n} \sum_{i=1}^{n} m_{i}\left(A_{k}\right)
$$

\subsection{Calculate the Deviation of Each Evidence to the Average} Evidence $d_{i}$

$$
\begin{aligned}
d_{i} & =\left\|m_{i}-\bar{m}\right\| \\
& =\sqrt{\sum_{k=1}^{n}\left(m_{i}\left(A_{k}\right)-\bar{m}\left(A_{k}\right)\right)^{2}}
\end{aligned}
$$

\subsection{Set Evidence Credibility Rating Factor}

When the reliability level of the following formula is 5 , the formula of the weighting coefficient can be determined according to the value of the evidence according to the evidence credibility of each evidence:

$$
w_{i}=\left\{\begin{array}{l}
5 ; d_{\text {min }} \leq d_{i}<d_{\text {min }}+0.2 \Delta d \\
4 ; d_{\text {min }}+0.2 \Delta d \leq d_{i}<d_{\text {min }}+0.4 \Delta d \\
3 ; d_{\text {min }}+0.4 \Delta d \leq d_{i}<d_{\text {min }}+0.6 \Delta d \\
2 ; d_{\text {min }}+0.6 \Delta d \leq d_{i}<d_{\text {min }}+0.8 \Delta d \\
1 ; d_{\text {min }}+0.8 \Delta d \leq d_{i} \leq d_{\text {max }}
\end{array}\right.
$$

where $\Delta d=d_{\max }-d_{\min }$, the partition coefficient $c_{i}$ can be further obtained:

$$
c_{i}=\frac{w_{i}}{\sum_{i=1}^{n} w_{i}}
$$

\subsection{Calculate New Weighted Average Evidence}

$$
\tilde{m}\left(A_{k}\right)=\sum_{i=1}^{n} c_{i} m_{i}\left(A_{k}\right)
$$

\subsection{Iterate over $m$ with the D-S Rule}

$$
m=\overbrace{\tilde{m} \oplus \tilde{m} \oplus \cdots \oplus \tilde{m}}^{n-1}
$$

where: $n-1$ is the number of times the operator $\oplus$ performs D-S operations [10].

\section{Data Analysis}

\section{Basic Content of Evidence Theory}

After increasing the D-S evidence theory, the weight coefficient will change as the reliability level changes. The smaller the average evidence deviation is, the higher the confidence level is, the larger the weight is. Information fusion results of the samples under different reliability levels are shown in Table 4. 
Table 4. Results of fusion of different reliability levels

\begin{tabular}{|c|c|c|c|c|c|}
\hline & Reliability level & $m(A 1) \%$ & $m(A 2) \%$ & $m(A 3) \%$ & $m(X) \%$ \\
\hline \multirow{5}{*}{ Sample 0} & 1 & 49.55 & 18.32 & 0.00 & 32.13 \\
\hline & 3 & 68.38 & 14.47 & 0.00 & 17.15 \\
\hline & 5 & 87.74 & 9.28 & 0.00 & 2.98 \\
\hline & 7 & 93.41 & 6.36 & 0.00 & 0.23 \\
\hline & 9 & 97.23 & 2.64 & 0.00 & 0.13 \\
\hline \multirow{5}{*}{ Sample 1} & 1 & 10.80 & 55.71 & 20.00 & 13.49 \\
\hline & 3 & 7.46 & 72.23 & 16.56 & 3.75 \\
\hline & 5 & 3.24 & 85.67 & 10.28 & 0.81 \\
\hline & 7 & 1.61 & 92.11 & 6.24 & 0.04 \\
\hline & 9 & 0.12 & 98.34 & 1.52 & 0.02 \\
\hline \multirow{5}{*}{ Sample 2} & 1 & 8.15 & 45.79 & 24.74 & 21.32 \\
\hline & 3 & 5.27 & 65.76 & 17.65 & 11.32 \\
\hline & 5 & 3.25 & 82.36 & 12.46 & 1.93 \\
\hline & 7 & 1.51 & 92.43 & 5.65 & 0.41 \\
\hline & 9 & 0.72 & 95.32 & 3.73 & 0.23 \\
\hline \multirow{5}{*}{ Sample 3} & 1 & 17.86 & 17.57 & 55.61 & 8.96 \\
\hline & 3 & 13.32 & 12.16 & 71.69 & 2.83 \\
\hline & 5 & 9.31 & 7.26 & 83.24 & 0.19 \\
\hline & 7 & 3.67 & 1.88 & 94.38 & 0.07 \\
\hline & 9 & 1.18 & 0.52 & 98.25 & 0.05 \\
\hline \multirow{5}{*}{ Sample 4} & 1 & 15.88 & 42.94 & 20.53 & 20.65 \\
\hline & 3 & 10.24 & 61.32 & 17.82 & 10.62 \\
\hline & 5 & 6.52 & 80.33 & 11.14 & 2.01 \\
\hline & 7 & 3.13 & 89.75 & 6.65 & 0.47 \\
\hline & 9 & 1.78 & 93.64 & 4.58 & 0 \\
\hline
\end{tabular}

Comparing the fusion results of Table 4, the results of the sample 1 are normal, and the final judgment result is appropriate for cockroaches. When the moisture content of sample 2 is slightly lower, the result is judged to be more apt for cockroaches. When the acidity content of sample 3 is low, it is not suitable for cockroaches. When the sample 4 has a high reducing sugar content, the discrimination result is more suitable for a cockroach. It can be observed in the analysis results that the method can make a preliminary judgment on the exit conditions.

\section{Conclusion}

Aiming at the situation after the wine cellars, the detection system consisting of fuzzy theory and DS evidence theory makes extensive use of the wine cellar de- 
tection information to realize the effective fusion of the sensors, and scientifically predicts the situation of the wine cellars. The next round of utilization of the wine cellar and the feasibility of fermentation ensures that the next round of fermentation is safe and appropriate. In the future work, the situation will be created after the wine cellar is released, and the relationship will be analyzed in order to more accurately study the impact of the conditions on the entire fermentation process.

\section{Conflicts of Interest}

The authors declare no conflicts of interest regarding the publication of this paper.

\section{References}

[1] Ma, L.S. (2015) Effects of Different Seasons on the Yield and Quality of Luzhou-Flavor Liquor. Qilu University of Technology, Jinan.

[2] Chen, J.P., Yan, Y.G. and Liu X.K. (2016) Reliability Simulation Method Considering Environmental Factors and Credibility. Science Technology and Engineering, 16, 150-153.

[3] Yan, F., Xu, K.L. and Cui, Z.K. (2017) An Improved Layer of Protection Analysis Based on a Cloud Model: Methodology and Case Study. Journal of Loss Prevention in the Process Industries, 48, 23-25.

[4] Gao, H.B., Xie, G.T. and Liu, H.Z. (2017) Lateral Control of Autonomous Vehicles Based on Learning Driver Behavior via Cloud Model. The Journal of China Universities of Posts \& Telecommunications, 24, 10-17.

[5] Ma, S.D., Zhang, H.Z. and Yang, G.Q. (2017) Target Threat Level Assessment Based on Cloud Model under Fuzzy and Uncertain Conditions in Air Combat Simulation. Aerospace Science and Technology, 67, 49-53.

[6] Ding, W.J., Liu, Y.A. and Xue, S. (2016) Synthetic Method of Conflict Evidence Based on Evidence Value. Computer Engineering and Science, 38, 15-17.

[7] Yang, F. and Wang, X.X. (2010) Synthetic Method of Conflicting Evidence for D-S Evidence Theory. National Defence Industry Press, Beijing, 224-230.

[8] Li, H.S. and Pan, D. (2017) Multi-Photoelectric Detection Sensor Target Information Recognition Method Based on D-S Data Fusion. Sensors and Actuators A: Physical, 264, 117-122. https://doi.org/10.1016/j.sna.2017.07.049

[9] Guo, K.H. and Li, W.L. (2011) Combination Rule of D-S Evidence Theory Based on the Strategy of Cross Merging between Evidence. Expert Systems with Applications, 38, 13360-13366. https://doi.org/10.1016/j.eswa.2011.04.161

[10] Tian, D.M., Zhang, L. and Huo, D.Q. (2013) Optimization of the Conditions for the Production of Luzhou-Flavor Liquor by the Sorghum Distiller's Grains. Food and Fermentation Industry, 12, 119-122. 